\title{
Pyrolytic carbon felt electrode Inhibits Formation of Zinc Dendrites in Zinc Bromine Flow Batteries
}

\author{
Hang Lin $^{1, *}$, Lufei Bai ${ }^{1}$, Xu Han ${ }^{1}$, Yu Zhang ${ }^{1}$, Junyou Shi ${ }^{1,2, *}$ \\ ${ }^{1}$ Department of Chemical Engineering, Northeast Electric Power University, Jilin 132012, China. \\ ${ }^{2}$ Department of Forestry, Beihua University, Jilin 132012, China. \\ *E-mail: hilinhang@sina.com, bhsjy64@163.com.
}

doi: $10.20964 / 2018.12 .18$

Received: 24 July 2018 / Accepted: 16 September 2018 / Published: 5 November 2018

\begin{abstract}
Zinc bromine flow batteries (ZBFBs) can provide energy storage with a high energy density and good efficiency, at moderate costs. However, faster technical development at a large scale have restricted faster development. In particular, in the charging process, uneven deposition of zinc easily forms zinc dendrites and pierces the separator to cause serious self-discharge of the battery, which greatly reduces the coulombic efficiency and service life. Pyrolytic method can improve the electrochemical properties of the carbon felt (CF) and effectively promote the uniform deposition of zinc in the ZBFBs. In this work, we found that the zinc deposits formed on the $\mathrm{CF}$ surface after calcined at $500{ }^{\circ} \mathrm{C}$ are tight and uniform, and the deposition quality is much better than that of the untreated ones. In terms of performance, compared with the original $\mathrm{CF}$ as the negative electrode of the zinc-bromine battery, operating at a current density of $40 \mathrm{~mA} \mathrm{~cm}$, the coulombic efficiency increased from $91.8 \%$ to $99.3 \%$, and the energy efficiency increased from $71.8 \%$ to $81.9 \%$. Even at a current density of $80 \mathrm{~mA}$ $\mathrm{cm}^{-2}$, the energy efficiency is as high as $69.8 \%$.
\end{abstract}

Keywords: Uniform deposition, Zinc dendrites, Pyrolytic carbon, Carbon felt.

\section{FULL TEXT}

(C) 2018 The Authors. Published by ESG (www.electrochemsci.org). This article is an open access article distributed under the terms and conditions of the Creative Commons Attribution license (http://creativecommons.org/licenses/by/4.0/). 